\title{
Influência do número de sheds e da distância horizontal entre eles no desempenho da ventilação natural
}

\author{
Influence of the number of sheds and the horizontal \\ distance between them on the performance of natural \\ ventilation
}

\section{Marieli Azoia Lukiantchuki \\ Alessandra Rodrigues Prata-Shimomura Fernando Marques da Silva Rosana Maria Caram}

\section{Resumo}

ventilação natural é uma eficiente estratégia para o condicionamento
térmico passivo de edificações, e muitas vezes o seu potencial está
relacionado às decisões em projeto diferentes do modelo convencional.
Um exemplo são os sheds, aberturas na cobertura que funcionam como captadores ou extratores de ar, dependendo de sua localização em relação aos ventos dominantes. O objetivo do artigo é avaliar a influência do número de sheds e da distância entre eles no desempenho da ventilação natural. Os ângulos de incidência dos ventos analisados foram $0^{\circ}, 45^{\circ}, 135^{\circ}$ e $180^{\circ}$. A metodologia adotada foi simulação por Dinâmica dos Fluidos Computacional (CFD), utilizando o software CFX. Os resultados indicam que o aumento do número de sheds reduz a renovação de ar interna para as situações de extração e captação de ar. Por outro lado, o aumento da distância entre esses dispositivos, incrementa o fluxo de ar interno para os sheds captadores. No entanto, teve-se uma redução na renovação de ar para os sheds extratores de ar. Isso ocorre pela redução da área total das abertiras de saída de ar, que apresenta uma influência na vazão volumétrica do edifício. Nos sheds captadores de ar o incremento ocorre, pois, apesar do aumento da distância ter reduzido o número das aberturas de entrada de ar, torna os sheds mais efetivos para captar o fluxo de ar.

Palavras-chaves: Simulação CFD. Ventilação natural. Sheds extratores e captadores de ar. Distância entre sheds.

Marieli Azoia Lukiantchuki Universidade Estadual de Maringá Maringá - PR - Brasil

\section{Alessandra Rodrigues Prata- Shimomura Universidade de São Paulo São Paulo - SP - Brasil}

Fernando Marques da Silva Laboratório Nacional de Engenharia

isboa - Portugal

Rosana Maria Caram Universidade de São Paulo São Carlos - SP - Brasil

Recebido em 01/02/17 Aceito em 23/05/17

\section{Abstract}

Natural ventilation is an effective strategy for the passive thermal conditioning of buildings, and its potential is often connected with design decisions that differ from the conventional model. An example of that are sheds, which are openings in the roof that function as air extractors and collectors, depending on their location in relation to the prevailing winds. The aim of this paper is to evaluate the influence of the number of sheds and the distance between them on the performance of natural ventilation. The angles of incidence of the winds analysed were $0^{\circ}, 45^{\circ}$, $135^{\circ}$ and $180^{\circ}$. The methodology adopted was simulation by Computational Fluid Dynamics using the CFX software. The results indicate that increasing the number of sheds reduces the internal air renewal for the air extraction and collection. Increasing the distance between the sheds, increases the internal airflow for the air collector sheds. However, a reduction in renewal rates was observed in the air extractor sheds. This was due to the reduction of the air outlet total area, which influences the flow rate of the building. In the air collector sheds, the increase occurred because the sheds become more effective for air entrance despite the fact that an increased distance reduced the number of air inlet openings.

Keywords: CFD simulation. Natural ventilation. Air extractors and collectors shed roofs. Distance between the sheds.

LUKIANTCHUKI, M. A.; PRATA-SHIMOMURA, A. R.; SILVA, F. M. da; CARAM, R. M. Influência do número de sheds e da distância horizontal entre eles no desempenho da ventilação natural. Ambiente Construído, Porto Alegre, v. 18, n. 2, p. 161-176, abr./jun. 2018. 


\section{Introdução}

O uso da ventilação natural em regiões de clima quente e úmido, como a maior parte do território brasileiro, é considerado uma estratégia eficiente para obtenção do conforto térmico por meios passivos, podendo contribuir de modo significativo para a redução do consumo de energia elétrica (CÂNDIDO et al., 2010). A circulação de ar natural deve estar acoplada cada vez mais ao processo de projeto do edifício, uma vez que o escoamento do fluxo de ar numa edificação demanda soluções mais complexas do que a simples abertura de uma janela. Ou seja, o aproveitamento do potencial da ventilação natural está estritamente relacionado às decisões de projeto, requerendo o emprego dessa estratégia passiva com uma abordagem arquitetônica diferenciada do modo convencional (COTTA; VIEIRA, 2015).

Diante do exposto, diferentes estratégias projetuais para o aproveitamento da ventilação natural têm sido empregadas nos edifícios, como chaminé solar, peitoril ventilado, torres de vento, parede trombe e os sheds. Os sheds são soluções de ventilação natural ao nível da cobertura que podem ser projetados tanto para extração como para captação do ar, dependendo da orientação de suas aberturas em relação aos ventos dominantes:

(a) nos sheds extratores, a abertura de entrada de ar se localiza em um nível mais baixo da fachada a barlavento e as aberturas de saída estão na cobertura, na fachada a sotavento;

(b) nos sheds captadores, as aberturas de entrada de ar estão em um nível superior (próximo à cobertura), na fachada a barlavento, e a abertura de saída de ar em um nível inferior, na fachada a sotavento (Figura 1).

Comparado com as coberturas planas, os sheds admitem a ventilação e a iluminação naturais, podendo contribuir ainda mais para o conforto térmico dos usuários e para ambientes internos mais saudáveis (LUKIANTCHUKI, 2015; PERÉN et al., 2016).

O desenho mais comum para esses dispositivos, conhecidos como "dentes de serra", é em formato ortogonal e sem muitas variações. No entanto, destaca-se o trabalho do arquiteto João Filgueiras Lima, Lelé, cujos sheds com formatos aerodinâmicos funcionando como captadores ou extratores de ar estão presentes na maioria de seus projetos (Figura 2), buscando melhorar a eficiência desses dispositivos com relação à ventilação natural. Em alguns casos, Lelé prioriza a entrada dos ventos por galerias subterrâneas e a extração do ar pela cobertura por efeito chaminé. Em outros, a captação dos ventos é realizada pela cobertura, propiciando uma corrente de ar permanente, que, além de ventilar os ambientes internos, permite a proteção térmica do edifício, o que reduz os ganhos de calor devido à radiação solar que incide diretamente pela cobertura (LUKIANTCHUKI et al., 2016).

O formato desses dispositivos para a ventilação natural é de grande importância, pois, segundo Hoof, Blocken e Aanen (2011), a geometria do edifício é um dos principais parâmetros que influem no uso dessa estratégia passiva Internacionalmente, muitos estudos têm sido desenvolvidos para telhados com uma água inclinada (GANDEMER et al., 1992; PREVATT; ASCE; ASCE, 2010; TORRES; ADELINO; BITTENCOURT, 2013), com várias águas no formato dente-de-serra (STATHOPOULOS; SAATHOFF, 1992; HOLMES, 1983; BLACKMORE, 1986) e coberturas em sheds aerodinâmicos (LUKIANTCHUKI et al., 2014; PERÉN et al., 2015). No entanto, a maioria das publicações estudadas sobre o assunto refere-se ao shed com formato ortogonal, sem considerar outras variações geométricas.

Figura 1 - Ventilação natural através de sheds extratores e captadores de ar

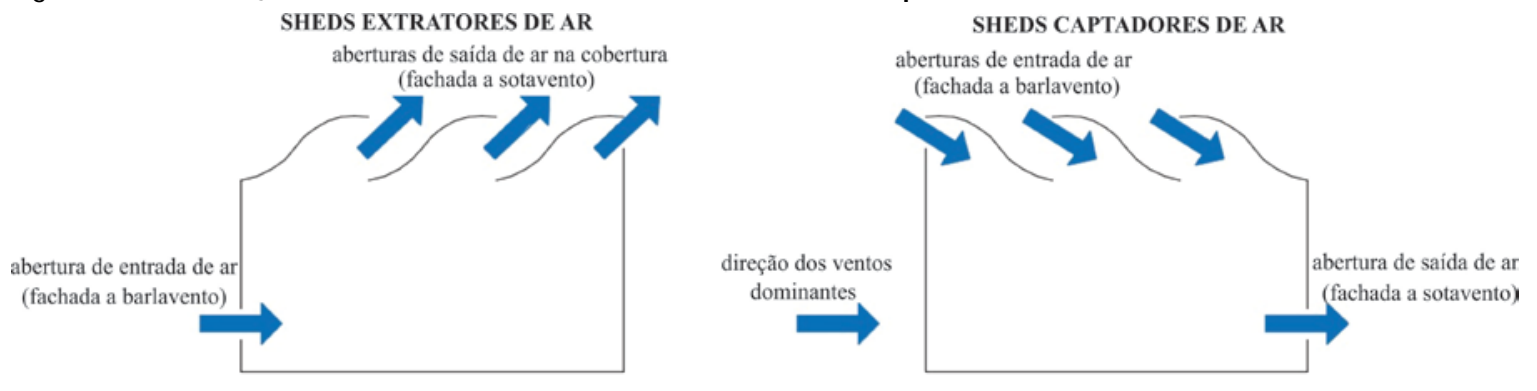

162 Lukiantchuki, M. A.; Prata-Shimomura, A. R.; Silva, F. M. da; Caram, R. M. 
Figura 2 - Sheds com formatos aerodinâmicos projetados por Lelé

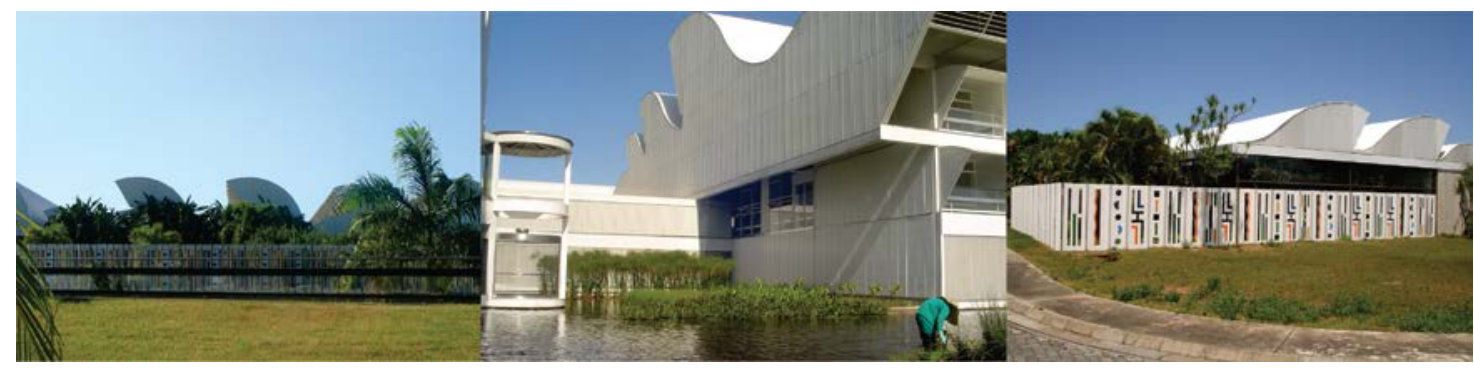

Fonte: Lukiantchuki (2015).

A influência de diferentes geometrias de sheds extratores e captadores de ar e a relação das dimensões das aberturas de entrada e saída de ar no desempenho da ventilação natural nos ambientes internos foram estudadas por Lukiantchuki et al. (2016). Os autores concluíram que para qualquer dos modos de funcionamento o modelo aerodinâmico gerou ganhos nas condições internas de circulação do ar. Isso ocorreu devido ao efeito de separação ocasionado por essa geometria, aumentando localmente as velocidades e reduzindo os valores dos coeficientes de pressão (Cp) nas aberturas dos sheds. Já com relação à variação da dimensão das aberturas registraram-se ganhos sempre que a abertura de exaustão aumentou. Ressalta-se que o aumento da abertura de entrada de ar também é um fator importante para os extratores, ao contrário dos sheds captadores, cujo aumento isolado desse parâmetro projetual sofre a influência de outros fatores como a menor distância entre os sheds localizados na mesma altura. Essa configuração impossibilita a entrada de ar pelos dispositivos localizados na região posterior, o que reduz a velocidade do ar nos ambientes internos.

Tendo-se como referencial os resultados da revisão da literatura, verificou-se uma lacuna em pesquisas sobre o impacto de diferentes configurações de sheds - como o número desses dispositivos na cobertura e a distância entre eles - no desempenho da ventilação natural em edifícios. Com essa constatação, o presente trabalho volta-se para a investigação de estratégias de incremento da ventilação natural nos espaços internos, tendo como objetivo central avaliar a influência do número de sheds com formato aerodinâmico e da distância entre eles no desempenho desses dispositivos como extratores e captadores de ar.

\section{Método}

A consecução do objetivo estabelecido foi operacionalizada nas seguintes etapas:

(a) seleção dos casos analisados; (b) seleção dos dados climáticos; e

(c) simulação computacional.

\section{Seleção dos casos analisados}

Essa pesquisa foi realizada com base na análise de dois parâmetros de projeto - número de sheds na cobertura e distância horizontal entre eles -, a fim de verificar suas influências sobre o desempenho de sheds extratores e captadores de ar. A geometria aerodinâmica dos sheds analisados foi selecionada com base naquela que apresentou o melhor desempenho na pesquisa de Lukiantchuki et al. (2016). O trabalho foi desenvolvido para diferentes valores de cada parâmetro projetual, sendo que para analisar as diferentes configurações, modificou-se um parâmetro por vez, de modo a identificar a sensibilidade do sistema para cada parâmetro isoladamente.

O caso de referência utilizado apresenta as mesmas características mencionadas em Lukiantchuki et al. (2016), denominada aqui de CS3, assim como a dimensão das aberturas adotada foi a que apresentou o melhor desempenho à ventilação no trabalho dos referidos autores. Todas as aberturas foram consideradas plenamente abertas durante as simulações.

O primeiro parâmetro analisado foi o número de sheds na cobertura. Essa variação modifica a área total das aberturas dos sheds e, consequentemente, o volume e a geometria externa do prédio. A análise desse parâmetro possibilita avaliar como um edifício com maior ou menor número de sheds e, consequentemente, maior ou menor profundidade influencia no desempenho da ventilação natural nos espaços internos. No entanto, o número de sheds, $\mathrm{n}$, por unidade de profundidade, $\mathrm{P}$, do edifício é mantido constante, o que pode ser caracterizado pelo parâmetro $\lambda=\mathrm{n} / \mathrm{P}$. Além do caso com três sheds na cobertura, analisaram-se edifícios com cinco e sete sheds. A Tabela 1 descreve os parâmetros avaliados. As características projetuais em destaque são as que 
sofreram alterações juntamente com o aumento do número de sheds na cobertura.

Por fim, no caso com maior profundidade, analisou-se a influência do aumento da distância entre os sheds no desempenho do fluxo de ar interno, através da alteração dos valores de Cp nas aberturas e das taxas de renovação de ar/hora. O aumento da distância entre esses dispositivos altera a configuração dos sheds da cobertura: o número desses dispositivos e a área total das suas aberturas. Analisaram-se quatro distâncias:
(a) 3,75 m;
(b) 5,00 m;
(c) $7,50 \mathrm{~m} ; \mathrm{e}$
(d) $15 \mathrm{~m}$.

Todas elas foram comparadas entre si e com o caso CS7, cuja distância é de 2,50 m. Essas variações são detalhadas na Tabela 2. Para esses casos, o parâmetro $\lambda=\mathrm{n} / \mathrm{P}$ sofreu alterações.

\section{Seleção dos dados climáticos}

O desempenho dos sheds foi avaliado para a velocidade máxima dos ventos externos igual a 7,0 $\mathrm{m} / \mathrm{s}$, definido com base na análise dos dados climatológicos do Instituto Nacional de Meteorologia (INMet) (2011), e dos arquivos no formato $\mathrm{Epw}^{1}$ elaborados por Roriz (2012). O valor definido é referente aos dados medidos nas estações climatológicas, a $10 \mathrm{~m}$ de altura, sendo utilizada a Equação 1 para a correção dessas velocidades na altura da edificação. Para as simulações computacionais adotou-se como entorno um ambiente suburbano com valor de $\alpha$ igual a 0,21 , obtido através de ensaios no túnel de vento $^{2}$, conforme descrito em Lukiantchuki et al. (2016).

$\frac{U}{U_{r e f}}=\left(\frac{h}{h_{r e f}}\right)^{\alpha}$

Onde:

$\mathrm{U}$ - velocidade média do vento em certa altura $\mathrm{h}$ $(\mathrm{m} / \mathrm{s})$;

$\mathrm{U}_{\text {ref }}$ - velocidade do vento medida na altura de referência $(\mathrm{m} / \mathrm{s})$;

$\mathrm{H}$ - altura da edificação que se deseja avaliar a velocidade do vento $(\mathrm{m})$;

$\mathrm{h}_{\text {ref }}$ - altura de referência da velocidade do vento (10 m); e

$\alpha$ - expoente de lei de potência da camada limite atmosférica (entorno).

Com relação aos ângulos de incidência dos ventos externos, os sheds foram avaliados como extratores $\left(0^{\circ}\right.$ e $45^{\circ}$, em relação à reta normal à abertura próxima ao piso) e captadores $\left(135^{\circ} \mathrm{e}\right.$ $180^{\circ}$ ) de ar (Figura 3). Foram considerados somente os dados de vento de velocidade e direção, uma vez que o objetivo é a avaliação da ventilação natural por ação dos ventos. A análise dos efeitos da diferença de temperatura entre o ar interno e externo (efeito chaminé) será realizada posteriormente.

\section{Tabela 1 - Características dos casos avaliados - variação do número de sheds na cobertura}

\begin{tabular}{l|l|l}
\hline \multicolumn{1}{c|}{ CS3 } & \multicolumn{1}{|c}{ CS5 } \\
\hline & & \\
\hline Distância sheds $=2,50 \mathrm{~m}$ & Distância sheds $=2,50 \mathrm{~m}$ & Distância sheds $=2,50 \mathrm{~m}$ \\
\hline Altura abert.fachada $=0,625 \mathrm{~m}$ & Altura abert.fachada $=0,625 \mathrm{~m}$ & Altura abert.fachada $=0,625 \mathrm{~m}$ \\
\hline Área abertura A1 $=3,12 \mathrm{~m}^{2}$ & Área abertura A1 $=3,12 \mathrm{~m}^{2}$ & Área abertura $\mathbf{A 1}=3,12 \mathrm{~m}^{2}$ \\
\hline Altura abert. Sheds $=0,625 \mathrm{~m}$ & Altura abert. Sheds $=0,625 \mathrm{~m}$ & Altura abert. Sheds $=0,625 \mathrm{~m}$ \\
\hline Área abert. sheds $=9,3750 \mathrm{~m}^{2}$ & Área abert. sheds $=15,62 \mathrm{~m}^{2}$ & Área abert. sheds $=21,87 \mathrm{~m}^{2}$ \\
\hline $\mathbf{N}^{\mathbf{0}}$ de sheds $=03$ & $\mathbf{N}^{\mathbf{0}}$ de sheds $=05$ & $\mathbf{N}^{\mathbf{0}}$ de sheds $=07$ \\
\hline Volume $=168,00 \mathrm{~m}^{3}$ & Volume $=280,50 \mathrm{~m}^{3}$ & Volume $=392,50 \mathrm{~m}^{3}$ \\
\hline Profundidade $=7,50 \mathrm{~m}$ & Profundidade $=12,50 \mathrm{~m}$ & Profundidade $=17,50 \mathrm{~m}$ \\
\hline$\lambda=0,4$ & $\lambda=0,4$ & $\lambda=0,4$ \\
\hline
\end{tabular}

${ }^{1}$ EPW (EnergyPlus Weather File).

${ }^{2} O$ s ensaios de avaliação da Camada Limite Atmosférica foram realizados no Laboratório Nacional de Engenharia Civil - LNEC, Lisboa Portugal (LUKIANTCHUKI, 2015). 
Tabela 2 - Características projetuais dos casos avaliados - variação da distância entre os sheds

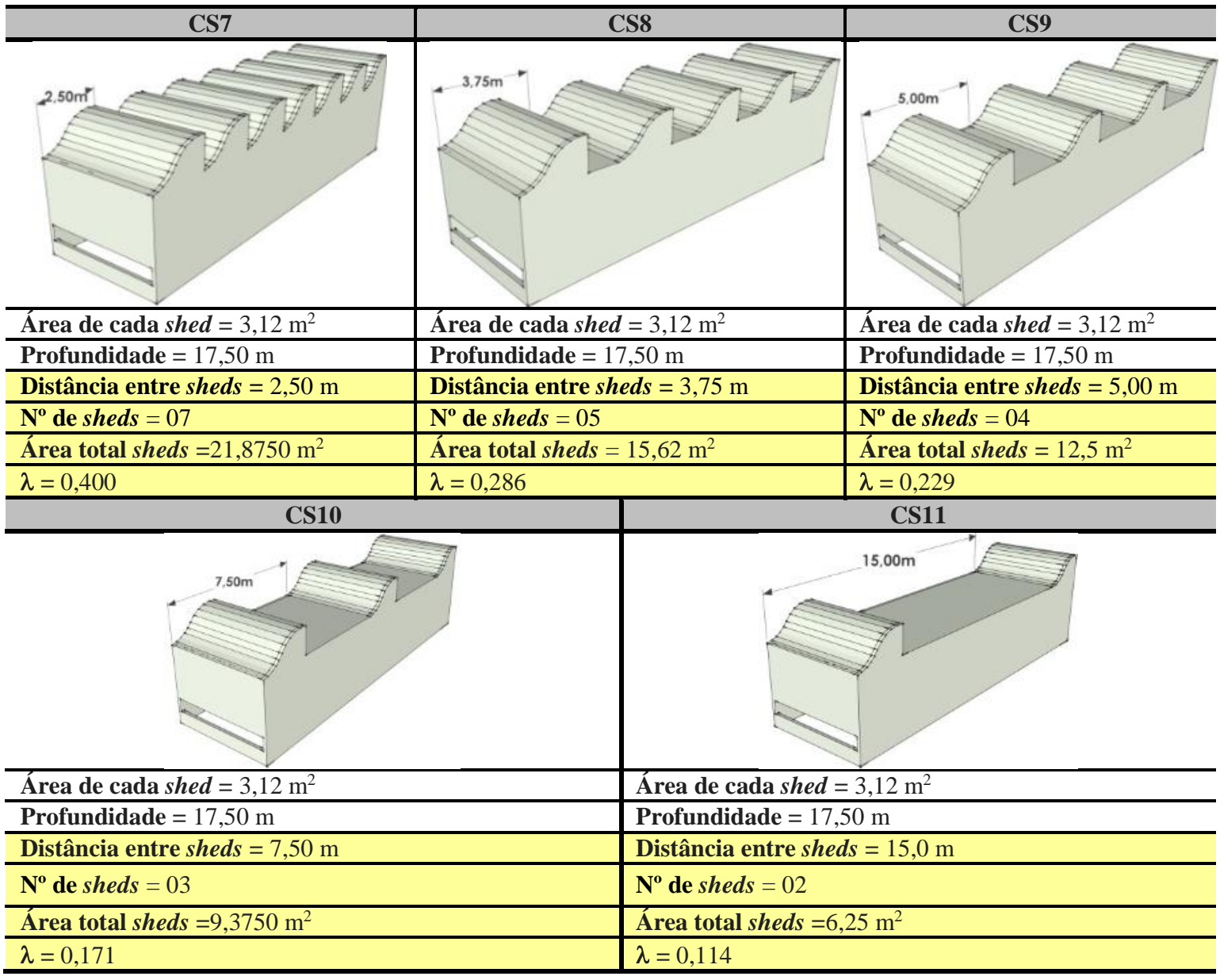

Figura 3 - Ângulos de incidência dos ventos externos analisados

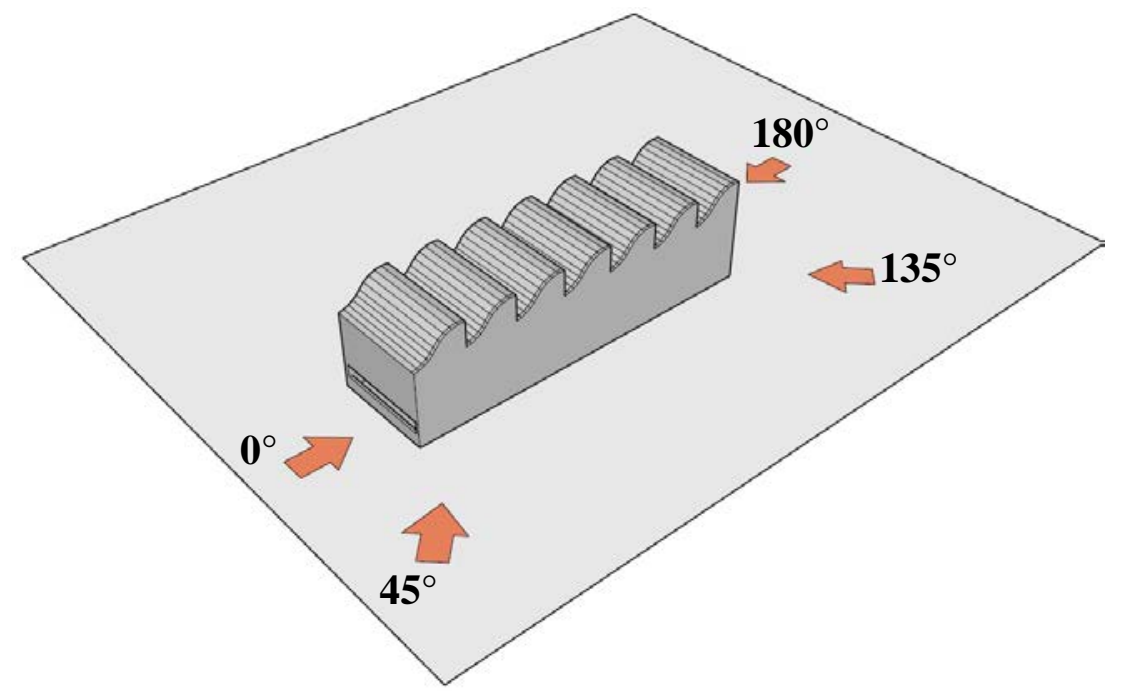

\section{Simulação computacional}

Para a realização das simulações, utilizou-se o software de Dinâmica dos Fluidos Computacional (CFD) CFX 12.0, Ansys. Essa ferramenta é adequada às pesquisas de análise de fluidos interno e externo nas áreas de engenharia e arquitetura. 


\section{Geração do modelo}

Os modelos tridimensionais do edifício e do domínio foram elaborados no software AutoCAD, exportando-os para o Icem. O domínio foi construído em um formato retangular, cujas dimensões seguiram as recomendações de Harries (2005) e Tominaga et al. (2008):

(a) distâncias a barlavento e nas laterais $=5 \mathrm{H}(25$ $\mathrm{m})$;

(b) altura $=6 \mathrm{H}(30 \mathrm{~m})$;

(c) distância a sotavento = 15H (75 m); e

(d) sendo $\mathrm{H}=5 \mathrm{~m}$, que corresponde à altura do modelo simulado (Figura 4).

Ramponi e Blocken (2012) testaram diferentes proporções de domínio e concluíram que em um domínio muito pequeno há tendência de aumento da velocidade local. A área de obstrução do edifício no domínio foi de $1,1 \%$, no sentido do fluxo e $1,0 \%$ no sentido perpendicular ao fluxo, atendendo à sugestão de Cost (2004) e Tominaga et al. (2008), que recomenda um valor abaixo de $3 \%$. Dessa forma, evita-se o efeito de blocagem, impedindo que as fronteiras do domínio influenciem no escoamento. Para cada ângulo de incidência dos ventos analisado, as dimensões do domínio foram modificadas para atender a essas recomendações.

\section{Geração da malha computacional}

A precisão dos resultados alcançados em uma simulação CFD é altamente dependente da qualidade da malha computacional e tem implicação no nível de convergência do modelo (CALAUTIT et al., 2013; HUGHES; CHAUDHRY; CALAUTIT, 2014). Para todas as simulações, utilizou-se uma malha estruturada tetraédrica, cujos parâmetros globais adotados foram: (a) maximum element size 16 ;

(b) natural size 4; $\mathrm{e}$

(c) cells in gap 8.

A malha foi refinada nas superfícies do edifício em um valor de $0,20 \mathrm{~m}$, a fim de melhorar a visualização do fluxo de ar no espaço interno e no entorno imediato ao edifício. A combinação desses parâmetros determina a quantidade de elementos da malha e, assim, o tempo de processamento das simulações (Figura 5). De acordo com Tominaga et al. (2008), para prever o fluxo em torno de um edifício com alta precisão, é importante reproduzir corretamente as características de separar os fluxos próximos da cobertura e das paredes, ou seja, é necessário o refinamento da malha nas áreas de interesse.

Recomenda-se que a sensibilidade dos resultados na resolução da malha seja testada, de forma a confirmar que o resultado não se altera significativamente com as diferentes resoluções da malha. A malha utilizada foi baseada em um teste de sensibilidade da malha computacional e os resultados podem ser encontrados em Lukiantchuki (2015).

\section{Definição das condições iniciais e de contorno}

A precisão de uma simulação CFD é afetada pelo modelo de turbulência, condições iniciais e de contorno. Nesta pesquisa, a definição desses fatores foi baseada em Cóstola e Alucci (2007) e Tominaga et al. (2008). As condições do domínio foram definidas de modo semelhante às de um túnel de vento: entrada como INLET e saída como OUTLET. As laterais e o teto como WALL free slip (sem atrito), pois não impõe resistência às partes do domínio onde não são realizadas análises importantes, e o piso e as superfícies do edifício como WALL no slip (com atrito).

Figura 4 - Dimensões adotadas para o domínio retangular

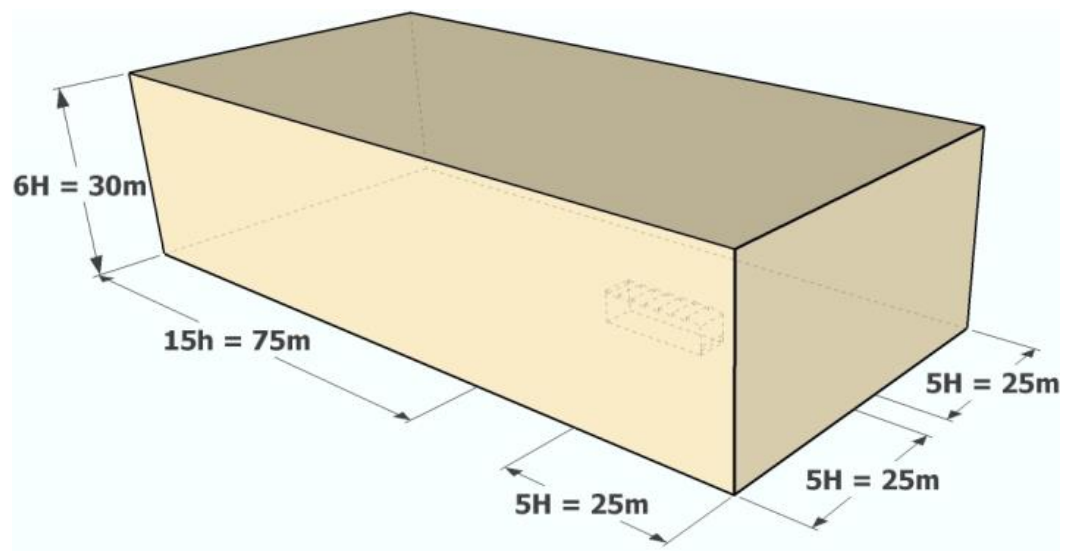

166 Lukiantchuki, M. A.; Prata-Shimomura, A. R.; Silva, F. M. da; Caram, R. M. 
Figura 5 - Detalhes da malha gerada para o caso CS7

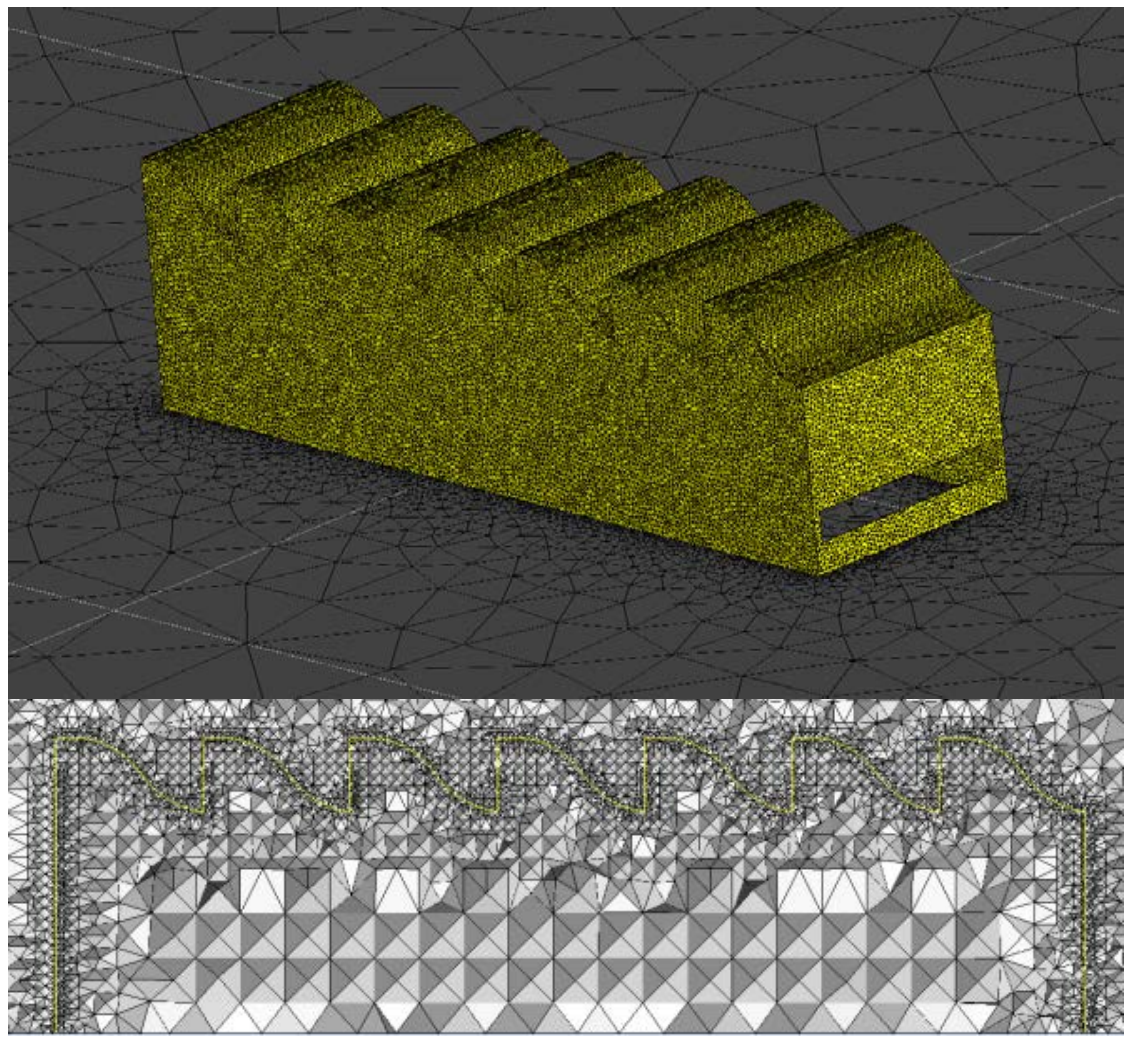

A simulação decorreu em regime permanente, na condição isotérmica a $25{ }^{\circ} \mathrm{C}$ (ação dos ventos). O mesmo perfil da camada limite atmosférica obtida experimentalmente em ensaios no túnel de vento (LUKIANTCHUKI, 2015) foi aplicado como condição de entrada nas simulações, utilizando a Equação 1. Os parâmetros adotados para a turbulência foram: a intensidade média (5\%), o valor padrão do software; e a high resolution advection scheme; conservative auto timescale.

O modelo de turbulência utilizado foi o K-epsilon, que é comum e bem estabelecido em diversas pesquisas de dinâmica dos fluidos e ventilação natural, conforme adotado e justificado no trabalho de Lukiantchuki et al. (2016). O nível de convergência foi estabelecido quando todos os níveis residuais alcançaram um valor máximo de $10^{-4}$. Os números de iterações mínimos e máximos adotados foram de 600 e 6.000 , respectivamente. Esses parâmetros foram baseados em pesquisas brasileiras sobre ventilação natural, utilizando como ferramenta o CFX (BRANDÃO, 2009; COSTA, 2009; CÓSTOLA, 2006, FIGUEIREDO, 2007; LEITE, 2008; PRATA, 2005).

\section{Tratamento dos resultados}

Para a análise do desempenho qualitativo da ventilação natural, foram gerados dois planos: um vertical, localizado no centro do edifício $(2,50 \mathrm{~m}) \mathrm{e}$ um horizontal, localizado no centro da abertura inferior, a 0,94 m do solo, na zona de ocupação dos usuários. Nesses planos foram plotados:

(a) contornos por gradação de cores, para as velocidades do ar; e

(b) vetores de intensidade e direção do fluxo de ar.

Foi utilizada uma escala em que cada cor representa um valor de velocidade e/ou de Cp correspondente. Posteriormente, para a análise do desempenho quantitativo, localizaram-se 3 pontos em cada abertura dos modelos avaliados, distantes uns dos outros em 1,25 m para medição da velocidade do ar e dos valores de Cp nas aberturas. A medição do Cp foi realizada através da inserção da equação ${ }^{3}$ para o cálculo dessa variável no CFX post. Em cada abertura, calculou-se a média do Cp e da velocidade do ar e, posteriormente, a vazão volumétrica e as taxas de renovação de ar. A nomenclatura utilizada nas aberturas foi: A1 para a abertura mais baixa e S1, S2,..., Sn (dependendo

3Pressure/ (1/2*ave(Density)@INLET*ave(Velocity)@P1^2). 
do número $n$ desses dispositivos na cobertura) para as aberturas dos sheds.

\section{Resultados}

Primeiramente, analisou-se a influência da variação do número de sheds e, consequentemente, da profundidade do edifício, no desempenho desses dispositivos com relação à ventilação natural. Posteriormente, a influência da variação da distância entre esses dispositivos foi avaliada. As análises foram realizadas de duas formas:

(a) qualitativa (planos de contorno e vetores de direção e intensidade do fluxo de ar); e

(b) quantitativa (taxas de renovação de ar/hora e Cp nas aberturas dos modelos).

\section{Variação do número de sheds}

A influência do número de sheds no desempenho do fluxo de ar interno foi analisada em função de diferentes ângulos de incidência dos ventos externos. A Figura 6 apresenta a variação nas taxas de renovação de ar/hora (\%), em relação ao CS3, e a Figura 7 os valores médios de $C p$ nas aberturas de entrada e saída de ar, para os diferentes ângulos de incidência dos ventos, em cada caso analisado.

De modo geral, o aumento do número de sheds exerceu uma influência expressiva no desempenho do fluxo de ar interno, reduzindo significativamente a renovação do ar no ambiente interno, tanto para os sheds extratores quanto para os captadores de ar, e que essa redução foi mais intensa para o segundo modo de funcionamento.

Figura 6 - Variação nas taxas de renovação de ar/hora (\%) em relação ao CS3, para diferentes ângulos de incidência dos ventos externos

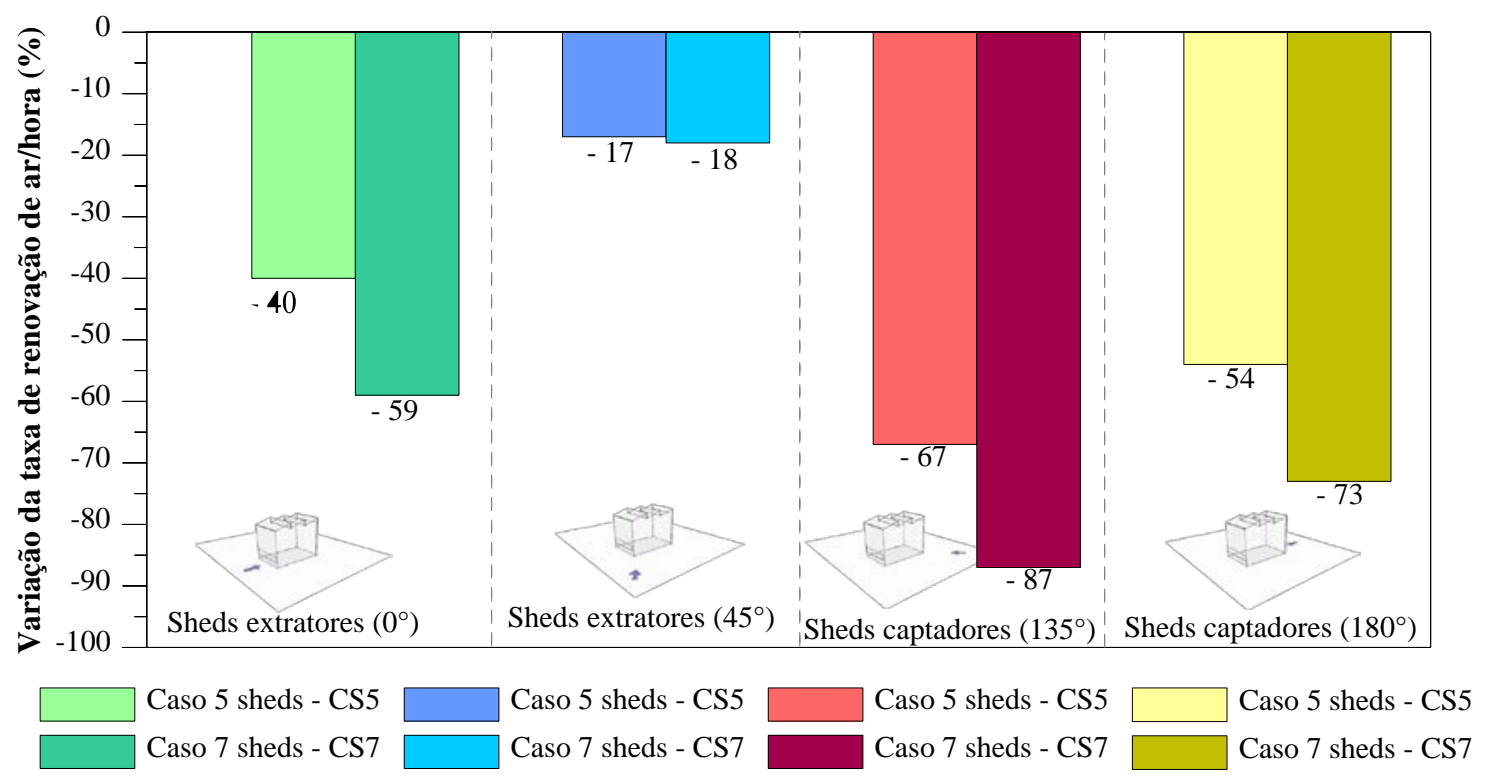

Figura 7 - Valores médios de Cp nas aberturas de entrada e saída de ar, para diferentes ângulos de incidêncis dos ventos enternos

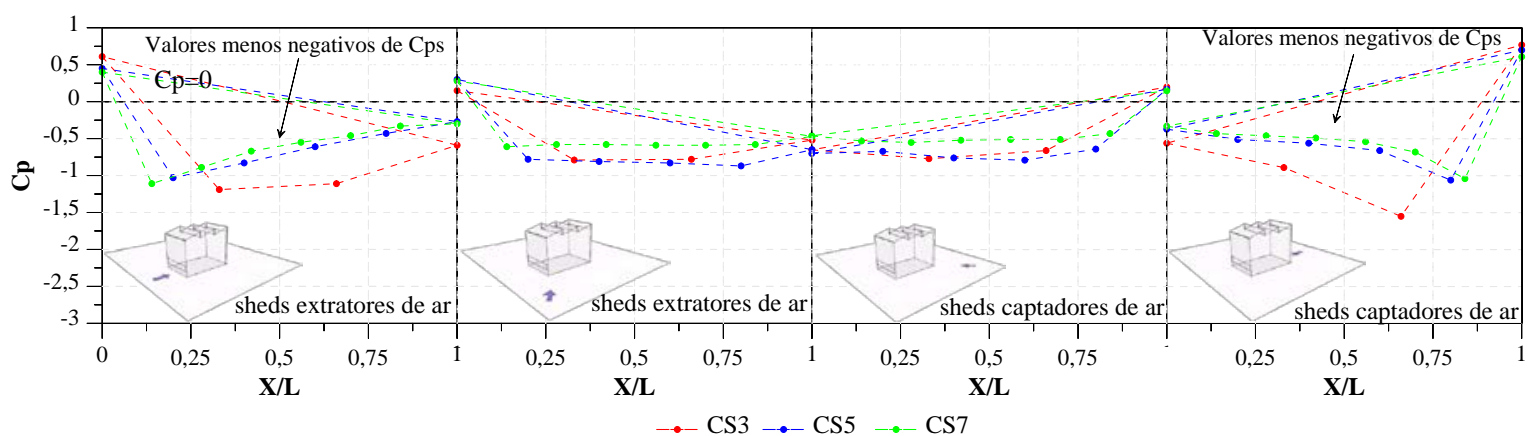

168 Lukiantchuki, M. A.; Prata-Shimomura, A. R.; Silva, F. M. da; Caram, R. M. 


\section{Sheds extratores de ar}

Para os sheds extratores de ar, apesar do acréscimo da área total das aberturas de saída de ar, decorrente do aumento do número de sheds na cobertura, notou-se uma redução na renovação do ar no ambiente interno, sendo essa redução mais significativa para o ângulo de incidência dos ventos de $0^{\circ}$ (de $40 \%$ e $59 \%$ para CS5 e CS7, respectivamente) em comparação com o ângulo de $45^{\circ}$ (de $17 \%$ e $18 \%$ para CS5 e CS7, respectivamente). Essa redução ocorreu essencialmente devido à interferência aerodinâmica entre os sheds e ao aumento da profundidade do edifício, reduzindo a velocidade do fluxo de ar interno nas regiões mais afastadas da face a barlavento e, consequentemente, a vazão volumétrica interna. De CS3 para CS5 houve uma redução da velocidade do fluxo de ar interno de aproximadamente $7 \%$ e de CS3 para CS7 esse valor foi mais significativo, registrando um fluxo de ar interno com velocidade 19\% menor (Figura 8).

Além disso, foi possível notar maior redução da velocidade do fluxo de ar na parte interna próxima aos sheds, à medida que se aumentou o número desses dispositivos. Ao contrário de CS3, em que o fluxo de ar é impulsionado com maiores velocidades para a região frontal, a corrente de ar nos casos CS5 e CS7 entra nas cavidades dos sheds formando uma massa de ar quase estacionária. Como se vê na Figura 8, o(s) shed(s) centrais praticamente não contribuem para 0 processo de ventilação, independentemente do seu número. Essa redução da velocidade do ar na região superior do espaço (próxima aos sheds) tende a induzir a recirculação do ar nessa região e, consequentemente, a extração do ar tende a ocorrer de forma mais suave (Figura 8).

Esse comportamento se deve também ao fato de os valores de Cp nos sheds próximos da face a barlavento (S1) possuírem valores mais negativos, devido ao fluxo de ar com maiores velocidades, acentuando-se as reduções nos valores de pressão. À medida que vai se afastando dessa face, o vento que tangencia os sheds retoma o contato com a cobertura, devido ao aumento do comprimento do edifício, gerando valores de $\mathrm{Cp}$ menos negativos. Devido a esse comportamento, os Cps não reduziram intensamente e, portanto, os casos mais profundos (CS5 e CS7) apresentaram menores $\Delta \mathrm{Cp}$ entre as aberturas de entrada e saída de ar e, assim, a extração não foi intensificada (Figura 7).

\section{Sheds captadores de ar}

Para os sheds captadores, embora o acréscimo do número de sheds tenha aumentado a quantidade de aberturas para a entrada de ar, foram registradas as maiores reduções na renovação do ar no espaço interno. A redução mais intensa ocorreu quando os ventos incidem nas aberturas a $135^{\circ}$, registrando para CS5 e CS7 reduções de $67 \%$ e $87 \%$, respectivamente, e de $54 \%$ e $73 \%$, respectivamente, para $180^{\circ}$ (Figura 6).

Em todos os casos, a entrada do ar continuou ocorrendo apenas pelo primeiro shed, sendo o fluxo captado extraído pelos sheds intermediários, sem incremento de ar na zona de ocupação dos usuários. Esse efeito é intensificado em CS5 e CS7, pelo aumento da profundidade do edifício, reduzindo ainda mais a velocidade na região afastada do shed captador. Isso ocorre também, pois o fluxo de ar captado pela cobertura atingiu a mesma distância interna, independentemente da quantidade desses dispositivos. Apesar do aumento do número de aberturas de entrada, nem todas são efetivas para a captação devido à sombra de vento gerada pelo ar que tangencia os sheds. Dessa forma, tem-se a movimentação de ar com baixas velocidades na zona de ocupação dos usuários (Figura 9).

\section{Figura 8 - Planta e corte da velocidade do fluxo de ar interno para os casos CS3, CS5 e CS7 - $0^{\circ}$}

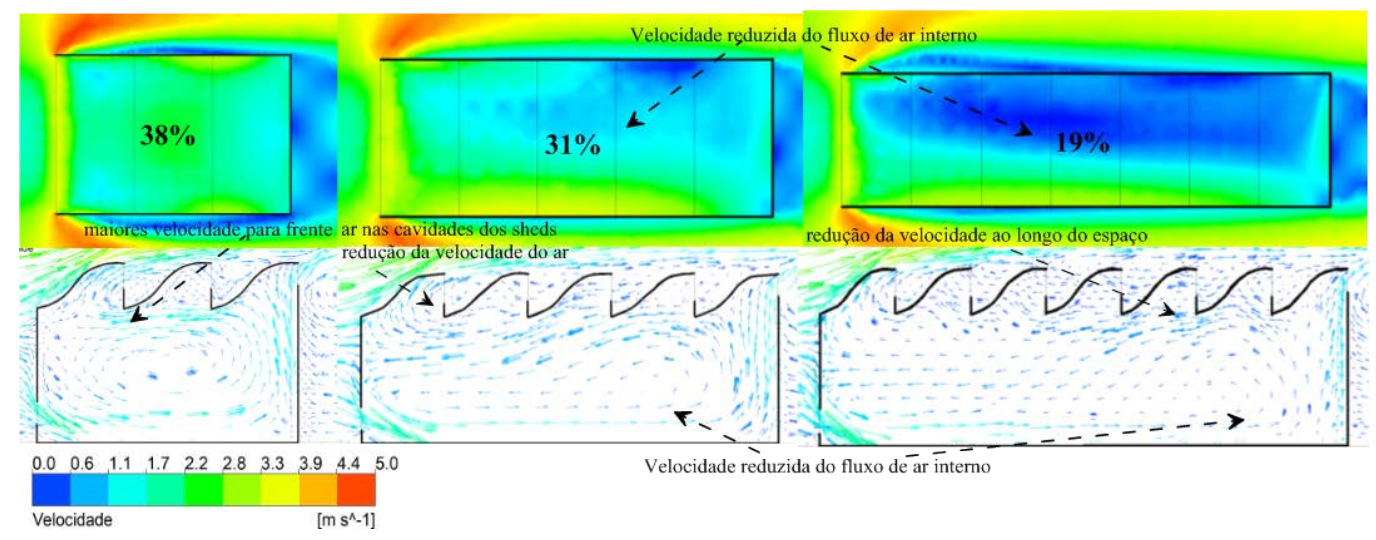


Figura 9 - Planta e corte da velocidade do fluxo de ar interno para CS3, CS5 e CS7 - $180^{\circ}$

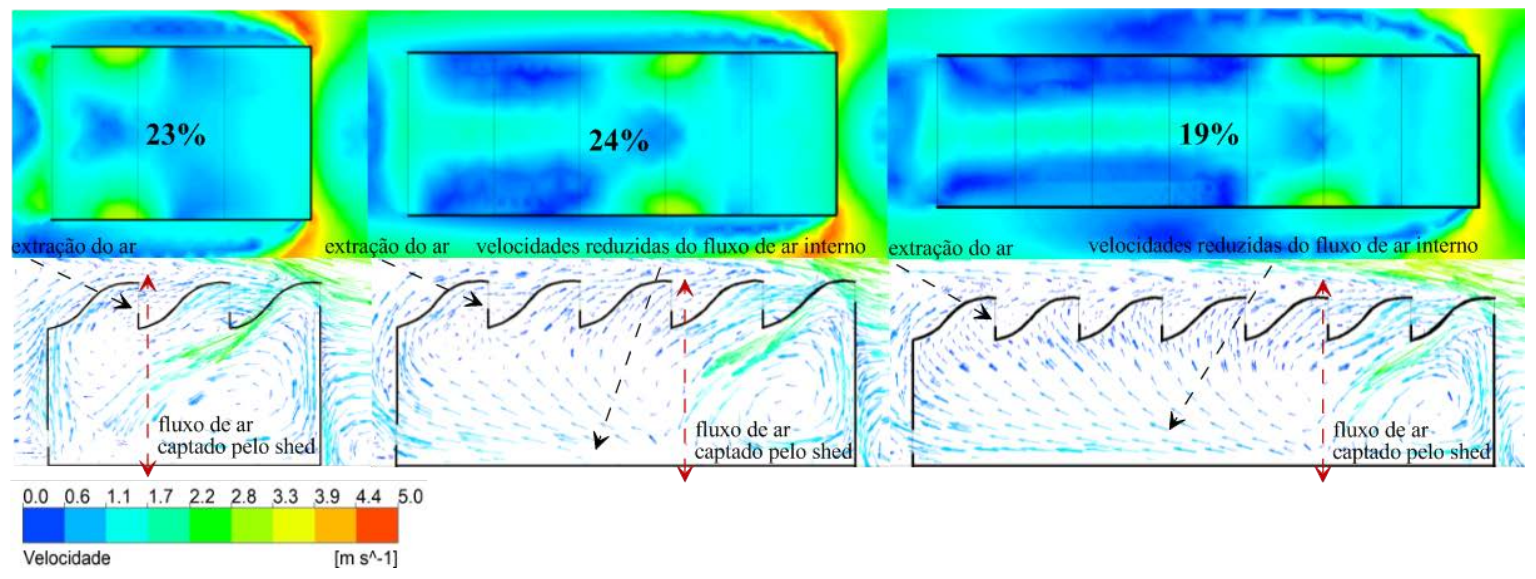

Os valores foram muito similares em todos os casos analisados, com exceção de CS7, cujas velocidades tiveram uma redução de $4 \%$ em relação ao CS3 (Figura 9). Nota-se que a região interna com baixas velocidades teve um aumento à medida que o número de sheds foi aumentando e, consequentemente, a profundidade do edifício. Parâmetros projetuais como o aumento do número de sheds e da profundidade do edifício influenciaram significativamente no desempenho da ventilação natural nos espaços internos, tanto para extração quanto para captação de ar (Figura 9).

O aumento do número desses dispositivos ocasionou valores menos negativos de $\mathrm{Cp}$ nas aberturas dos sheds localizados mais distantes da face a barlavento (menores $\Delta \mathrm{Cp}$ entre as aberturas), devido ao aumento da profundidade do edifício. Não se verifica o recolamento do escoamento (como na incidência de $0^{\circ}$ ) porque as arestas vivas de S3 impõem uma separação (sombra de vento) mais intensa. No caso de $135^{\circ}$, nota-se a similaridade entre os valores de Cp nos casos avaliados (Figura 7).

Dos casos analisados, o que apresentou o pior desempenho, tanto para extração quanto para captação de ar, foi o CS7, sendo que para os sheds extratores de ar essa redução é mais intensa. Como $\lambda$ é constante significa que apenas foram acrescentados sheds ineficientes, que não contribuem para o aumento da renovação do ar interior. As taxas diminuem porque o volume interno aumenta, mas o fluxo de renovação não apresentou um incremento da mesma forma. Assim, com o objetivo de estudar como melhorar o fluxo de ar interno no caso que apresentou o pior desempenho, analisou-se também a influência da variação da distância entre os sheds, ou seja, variando $\lambda$ total, no desempenho do fluxo de ar interno, para diferentes ângulos de incidência dos ventos.

\section{Variação da distância entre os sheds}

As Figuras 10 e 11 apresentam a variação (\%) nesses valores com o aumento da distância entre os sheds, em relação ao caso com a distância padrão de 2,50 m (CS7) e os valores de Cp médios nas aberturas de entrada e saída de ar, respectivamente, para os diferentes ângulos de incidência dos ventos externos analisados.

\section{Sheds extratores de ar}

De maneira geral, para os sheds extratores de ar, o aumento da distância entre esses dispositivos reduziu a área total das aberturas de saída de ar em $29 \%, 43 \%$, 58\% e $71 \%$ para os casos CS8, CS9, CS10 e CS11, respectivamente, em relação ao caso CS7, o que diminuiu as taxas de renovação de ar/hora (Figura 10), embora com valores pouco significativos para $\lambda>0,171$. À medida que se aumenta a distância entre os sheds, tem-se uma redução na renovação do ar interno de 2\%, 4\%, 6\% e $14 \%$, para valores $0,286>\lambda<1,114$ respectivamente, e para o ângulo de incidência de $0^{\circ}$. Para CS8 a CS10 a variação é negligenciável e mesmo para CS11 está na faixa normal de erro admissível. Essa redução foi mais significativa quando os ventos incidem obliquamente no edifício (45): 14\%, 24\%, 42\% e 62\% (Figura 10), situação em que a redução de área é preponderante. 
Figura 10 - Variação nas taxas de renovação de ar/hora (\%) em relação ao CS7, para diferentes ângulos de incidência dos ventos externos

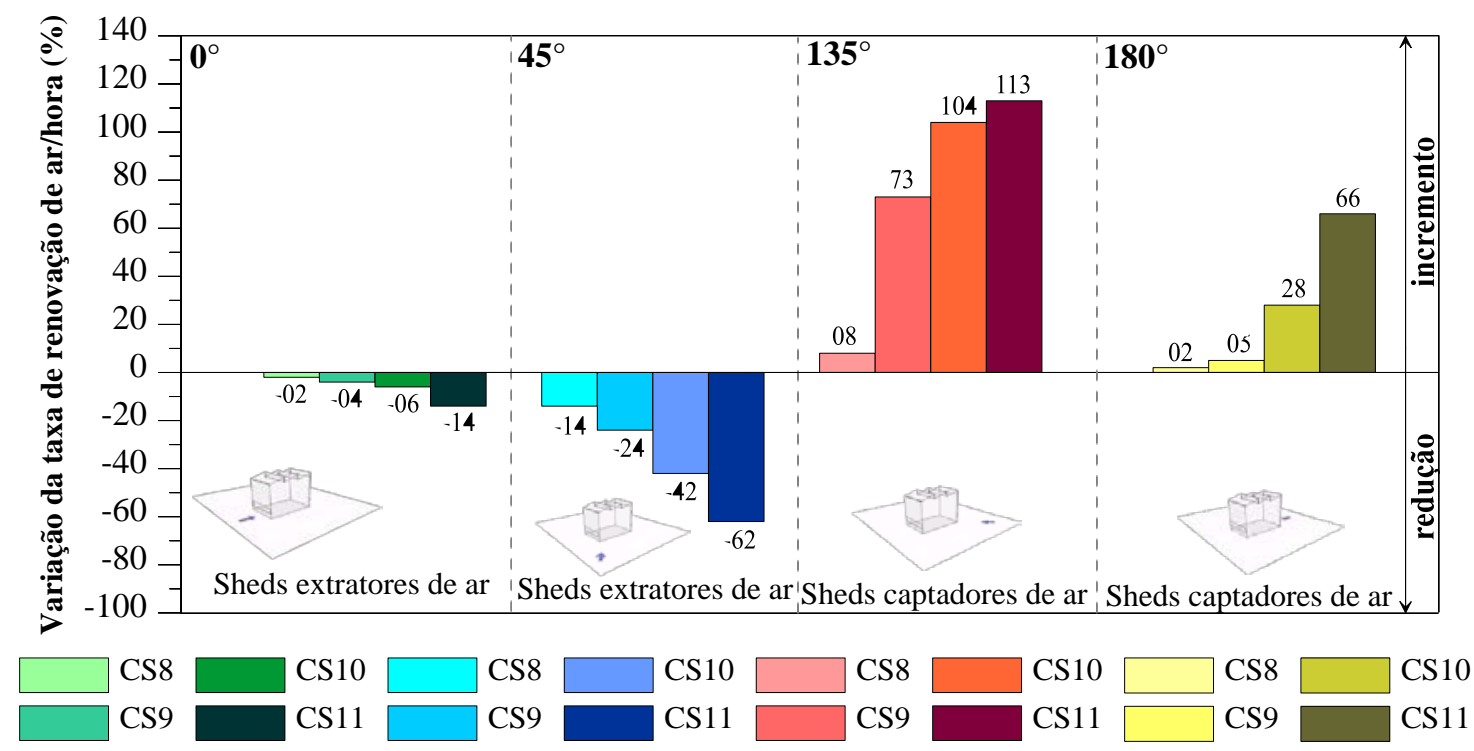

Figura 11 - Valores médios de Cp nas aberturas de entrada e saída de ar, para diferentes ângulos de incidência dos ventos externos

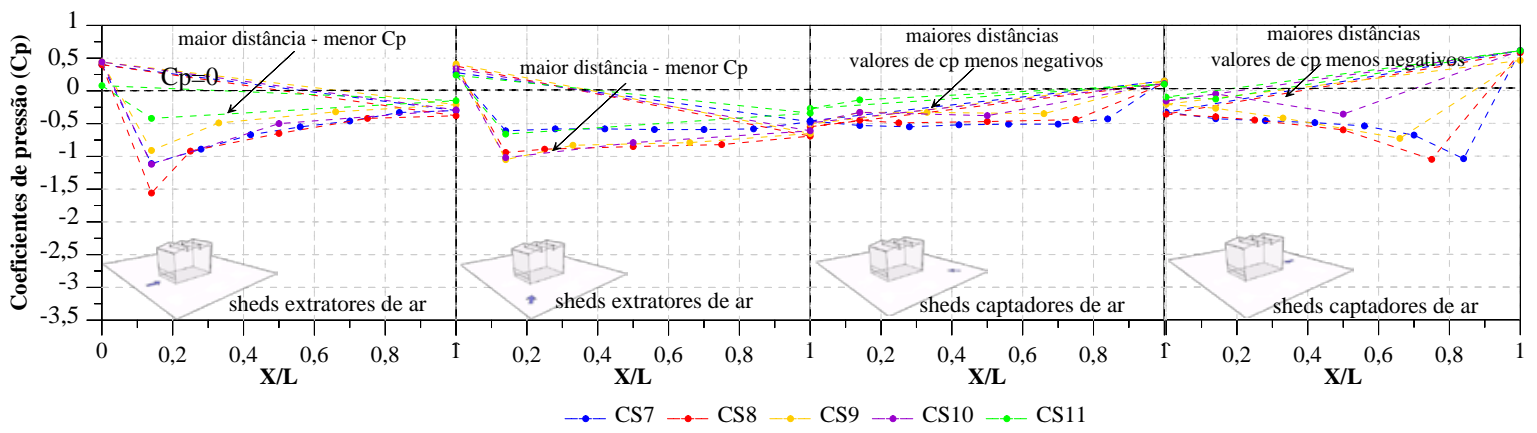

A redução no desempenho da ventilação natural no espaço interno para os sheds extratores foi confirmada pelo $\mathrm{Cp}$, cujos valores nas aberturas dos sheds mais próximos da face a barlavento possuem valores mais negativos, em virtude do fluxo de ar tangenciar os primeiro sheds com maiores velocidades. À medida que a distância é aumentada, o vento incide na cobertura com redução na velocidade, o que ocasiona $\mathrm{Cp}$ menos negativos nos sheds mais afastados da face a barlavento (menores $\Delta \mathrm{Cp}$ ) e, portanto, um fluxo de ar interno com menores velocidades (Figura 11). Estando esses dispositivos localizados mais próximos uns dos outros (CS7), os sheds a barlavento exercem maior influência sobre os sheds localizados na zona posterior (sotavento), o que ocasiona a formação de massas de ar com zonas de recirculação nas aberturas dispostas na cobertura. À medida que a distância foi aumentada, essas recirculações de ar nas aberturas foram reduzidas, sendo esse efeito para a distância de 15 m (CS11) praticamente extinto (Figura 12).
A influência de $\lambda$ em Cp (S1), para a incidência de $0^{\circ}$, é evidente (Figura 11) e a redução de Cp (CS11) é devido à inversão do escoamento na cobertura (com ar penetrando na abertura) permitida pelo espaço entre os dois sheds (Figura 12). No entanto, para $45^{\circ}$ a influência de $\lambda$ nos valores de Cp também é clara, e para $0,286>\lambda<1,171$ os valores de Cp são mais eficazes.

Com o acréscimo da distância entre os sheds, aumenta-se o comprimento dos trechos de deslocamento horizontal que o ar percorre sob a cobertura até atingir uma abertura. Com isso, há redução de velocidade nas linhas de corrente de ar, pois passa a se deslocar na horizontal em busca de uma saída. Isso pode ser minimizado quando essa distância a ser percorrida pelo ar sob a cobertura, até ser extraído, é reduzida, assegurando fluxos de ar com maior velocidade e, portanto, uma ventilação no espaço interno mais eficiente (Figura 12). Nota-se que a redução das aberturas de saída de ar é um parâmetro que exerce grande influência 
na ventilação natural por meio de sheds extratores de ar e que quanto menores elas forem, menor o fluxo de ar no ambiente interno.

\section{Sheds captadores de ar}

Na situação de captação de ar, o aumento da distância entre os sheds ocasionou um leve incremento nas taxas de renovação de ar (Figura 10). Quando a distância foi aumentada para $3,75 \mathrm{~m}$ (CS8) - $\lambda=0,286$, esse aumento não foi muito significativo $\left(8 \%\right.$ e $2 \%$ em $135^{\circ}$ e $180^{\circ}$, respectivamente). Aumentando a distância para 5,00 m (CS9)- $\lambda=0,229$, tem-se uma clara melhoria nas taxas de renovação de ar de $73 \%$, para o ângulo de $135^{\circ}$, mas sem uma variação significativa (5\%) para a incidência de $180^{\circ}$. Para CS10 (distância de 7,50 m) $-\lambda=0,171$, notou-se um aumento mais significativo do fluxo de ar interno (104\% para o ângulo de $135^{\circ}$ em relação ao CS7 e $31 \%$ em relação ao CS9). Por fim, quando a distância é duplicada, passando para 15,0 m (CS11) $-\lambda=0,114$, tem-se o melhor desempenho, registrando um incremento de $113 \%$ e $66 \%$ para $135^{\circ}$ e $180^{\circ}$, respectivamente. No entanto, ao comparar o CS11 com o $\operatorname{CS} 10$ (7,50 m e $\lambda=0,171)$, o incremento foi menor para o ângulo de $135^{\circ}(9 \%)$, mostrando uma estabilização na ventilação interna a partir de uma determinada distância. Já para o ângulo de $180^{\circ}$ isso não foi registrado, uma vez que o aumento foi mais significativo (aumento de $38 \%$ em relação ao CS10) (Figura 10).

Apesar de o aumento da distância ter reduzido o número das aberturas de entrada de ar, esse incremento ocorreu porque os espaços maiores entre os sheds possibilitaram uma recuperação da velocidade do vento no nível da cobertura, permitindo a captação pelos sheds posteriores. Ou seja, os sheds "centrais" passaram progressivamente a ser efetivos e, mesmo com a drástica redução de área das aberturas, as taxas de renovação aumentaram. No caso com menor distância (CS7), tem-se sete aberturas para a entrada do ar, com uma área total de 21,8750 $\mathrm{m}^{2}$, ao contrário do caso cuja distância é de $15 \mathrm{~m}$ (CS11), em que se tem apenas duas aberturas de captação, com uma área total de $6,25 \mathrm{~m}^{2}$. No entanto, no CS7 a captação do ar é apenas pelo primeiro dispositivo, pois a sombra de vento gerada nos sheds posteriores, pelo ar que tangencia a cobertura, ocasionou uma queda de pressão (valores negativos de $\mathrm{Cp}$ ) que proporciona a extração do ar (Figuras 11 e 13).

\section{Figura 12 - Cortes da velocidade do fluxo de ar interno de todas as variações analisadas - $0^{\circ}$}

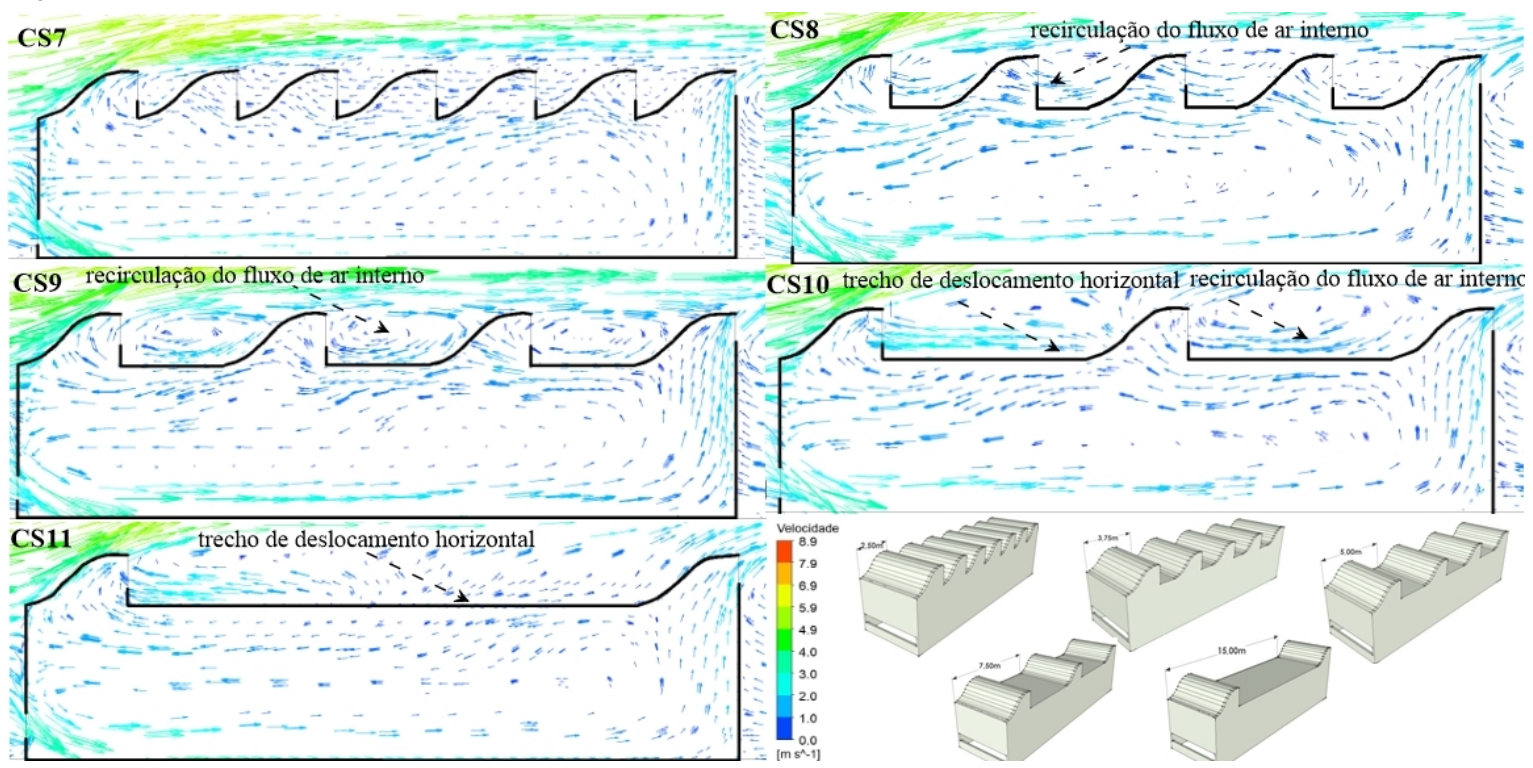

172 Lukiantchuki, M. A.; Prata-Shimomura, A. R.; Silva, F. M. da; Caram, R. M. 
Figura 13 - Cortes da velocidade do fluxo de ar interno de todas as variações analisadas - $180^{\circ}$

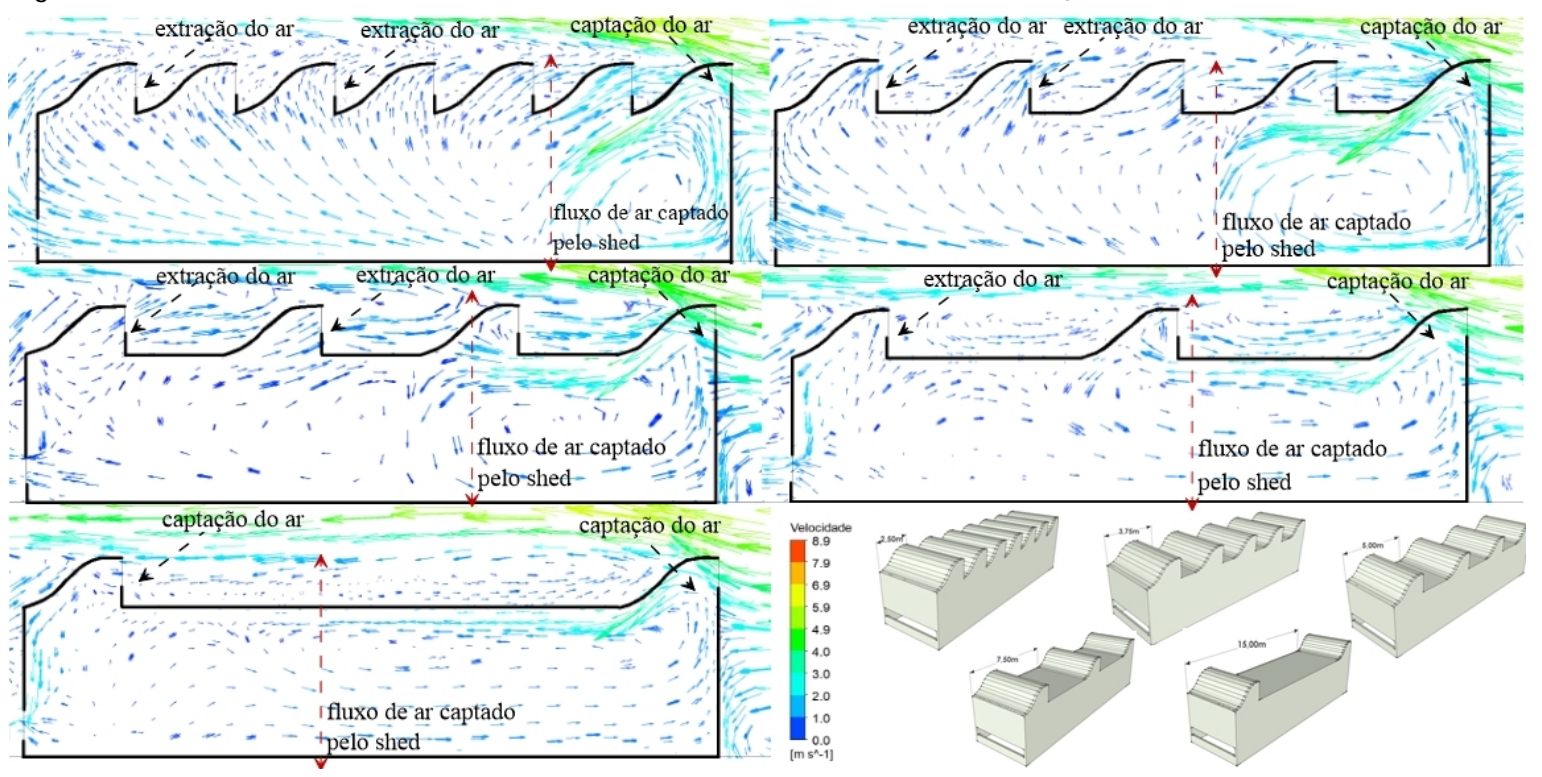

No CS11 isso não foi registrado, sendo a captação realizada pelas duas aberturas, o que possibilitou melhor distribuição do fluxo de ar interno e, assim, maiores velocidade do ar (Figura 13). Os valores de $\mathrm{Cp}$ nas aberturas tornaram-se menos negativos, com uma forte tendência para ficarem positivos à medida que a distância foi aumentada (menores valores de $\lambda$ ), evitando-se a extração da corrente de ar pelos sheds "centrais". Com isso, as aberturas se tornaram mais efetivas para a captação, evitando-se a extração da corrente de ar pelos sheds localizados na zona posterior ao primeiro dispositivo captador, conforme ocorria com CS7. Com o afastamento entre os sheds, a zona de escoamento separado é menos intensa, uma vez que a curvatura das linhas de corrente é menos pronunciada e, consequentemente, a pressão não fica sujeita a uma grande redução (Figuras 11 e 13). À medida que se aumentou a distância entre esses dispositivos, nota-se que a recirculação do ar também aumentou e o fluxo de ar com maiores velocidades captado pelo shed a barlavento atingiu uma região maior do espaço interno. Isso ocorreu em função das geometrias dos sheds e do aumento da distância que possibilitou uma parte plana na cobertura, direcionando o fluxo de ar para a região mais afastada do shed captador (Figura 13).

\section{Conclusões}

Para a avaliação da influência do número de sheds nas taxas de ventilação internas introduziu-se um parâmetro, $\lambda=n / P$, que relaciona o número de sheds com a profundidade do edifício, isto é, um indicador da densidade de ocupação da cobertura e/ou da proximidade entre esses elementos. Para um mesmo valor de $\lambda$ (igual a 0,4 ) o aumento do número de sheds reduziu as taxas de renovação de ar/hora (entre $17 \%$ e $59 \%$ para os sheds extratores de ar e entre $54 \%$ e $87 \%$ para os sheds captadores de ar). Nota-se que com $\lambda$ constante apenas estão sendo acrescentados sheds ineficientes que não contribuem para o aumento do fluxo de renovação de ar interior. Além disso, constatou-se que embora o volume interno tenha um aumento com a alteração desse parâmetro projetual, a ventilação natural no ambiente interno não apresenta um incremento na mesma proporção.

As variações do número de sheds na cobertura, mantendo a profundidade do edifício constante (variações de $0,400>\lambda<1,114$, permitiram comparar resultados e obter conclusões sobre a configuração que apresentou o comportamento menos eficaz. O desempenho das taxas de ventilação interna, em função de $\lambda$, diferem consoante a situação de extração ou captação de ar. No primeiro caso as variações (negativas) da taxa de renovação de ar somente são significativas para incidências de $45^{\circ}$ e para $\lambda<0,23$. No segundo caso as variações são sempre positivas e significativas para $\lambda<0,23$ (incidência de $135^{\circ}$ ) e para $\lambda<0,17$ (incidência de $180^{\circ}$ ).

Uma vez que as variações são em sentidos opostos nos dois modos e que não se verifica a sobreposição de faixas de $\lambda$ para um funcionamento mais eficaz (taxas suficientes, mas não excessivas), será necessário recorrer aos pressupostos do projeto de arquitetura e sua implantação no terreno. Isto é, se o modo mais eficaz de ventilar o interior for a admissão de ar pela cobertura, o edifício deverá ser orientado de 
modo que os sheds recebam o vento dominante e a configuração privilegie valores de $\lambda<0,17$. Caso contrário, se o modo indicado for o de extração do ar pela cobertura, o edifício deverá ter a orientação correspondente a $\lambda>0,23$. Em face desses resultados fica em aberto a exploração de outras formas que não apenas a linear e perpendicular à profundidade do edifício, de forma de ultrapassar essa discrepância entre as diferentes faixas de $\lambda$.

\section{Referências}

BLACKMORE, P. A. Wind Loads on Pitch Roof Multi-Span Buildings. Building Research Establishment, Note $N^{\circ}$ N120186. Dept. of Environment, Garston, Watford, U. K., 1986.

BRANDÃO, R. S. As Interações Espaciais Urbanas e o Clima. São Paulo, 2009. Tese (Doutorado em Arquitetura e Urbanismo) Faculdade de Arquitetura e Urbanismo, Universidade de São Paulo, São Paulo, 2009.

CALAUTIT, J. K. et al. CFD Analysis of a Heat Transfer Device Integrated Wind Tower System for Hot and Dry Climate. Applied Energy, v. 112, p. 576-591, 2013.

CÂNDIDO, C. et al. Aplicabilidade dos Limites de Velocidade do Ar Para Efeito de Conforto Térmico em Climas Quentes e Úmidos. Ambiente Construído, Porto Alegre, v. 10, n. 4, p. 59-68, out./dez. 2010.

COST. Cost Action 14: recommendations on the use of CFD in predicting pedestrian wind environment. Bruxelas: COST, 2004.

\section{COSTA, L. Aproveitamento da Ventilação}

Natural nas Habitações: um estudo de caso na cidade de Aracaju - SE. São Paulo, 2009. Dissertação (Mestrado em Tecnologia da Arquitetura) - Faculdade de Arquitetura e Urbanismo, Universidade de São Paulo, São Paulo, 2009.

CÓSTOLA, D. Ventilação Por Ação do Vento no Edifício: procedimentos para quantificação. São Paulo, 2006. Dissertação (Mestrado em Tecnologia da Construção) - Faculdade de Arquitetura e Urbanismo, Universidade de São Paulo, São Paulo, 2006.

CÓSTOLA, D.; ALUCCI, M. Pressure Coefficient Simulated by CFD For Wind-Driven Ventilation Analysis. In: BUILDING SIMULATION, Beijing, 2007. Proceedings... Beijing, 2007.
COTTA, J. O.; VIEIRA, J. L. O Desempenho Térmico de Ambientes de Trabalho nas Cidades de São Paulo e Rio de Janeiro. In: GONÇALVES, J. C. S.; BODE, K. Edifício ambiental. São Paulo: Oficina de textos, 2015.

FIGUEIREDO, C. A. Ventilação Natural em Edifícios de Escritórios na Cidade de São Paulo: limites e possibilidades do ponto de vista do conforto térmico. São Paulo, 2007. Dissertação (Mestrado em Tecnologia da Construção) Faculdade de Arquitetura e Urbanismo da Universidade de São Paulo, São Paulo, 2007.

GANDEMER, J. et al. Guide Sur la Climatisation Naturelle de L'habitat en Climat Tropical Humide. Tome 1: Methologie de prose em compte des parameters climatiques dans l'habitat et conseils pratiques. Report for the CSTB 1992.

HARRIES, A. Notas de aula. In: Workshop: CFX - FAU/USP. São Paulo, 2005.

HOLMES, J. D. Wind Loading of Multi-Span. In: FIRST National Structural Engineering Conference. Melbourne, 1983.

HOOF, B.; BLOCKEN, B.; AANEN, B. A Venturi-Shaped Roof For Wind-Induced Natural Ventilation of Buildings: wind tunnel and Computational Fluid Dynamic (CFD) evaluation of different design configurations. Building and Environment, v. 46, p. 1797-1807, 2011.

HUGHES, B. R.; CHAUDHRY H.N.; CALAUTIT, J. K. Passive Energy Recovery From Natural Ventilation air Streams. Applied Energy, v. 40, p. 113- 127, 2014.

INSTITUTO NACIONAL DE

METEOROLOGIA. [Sobre]. Disponível em: $<$ http://www.inmet.gov.br/>. Acesso em: 21 nov. 2011.

LEITE, C. G. Alterações da Ventilação Urbana Frente ao Processo de Verticalização de Avenidas Litorâneas: o caso da avenida litorânea de São Luís/MA. São Paulo, 2008. Dissertação (Mestrado em Arquitetura e Urbanismo) Faculdade de Arquitetura e Urbanismo. Universidade de São Paulo, São Paulo, 2008.

LUKIANTCHUKI, M. A. et al. Natural Ventilation by Captors and Extractors Sheds in Hospitals in Brazil: wind tunnel measurements. Journal of Civil Engineering and Architecture, v. 8, n. 10, p. 1293-1303, 2014. 
LUKIANTCHUKI, M. A. et al. Sheds Extratores e Captadores de Ar: influência da geometria e da dimensão das aberturas no desempenho da ventilação natural nas edificações. Ambiente Construído, Porto Alegre, v. 16, n. 1, p. 83-104, jan./mar. 2016.

LUKIANTCHUKI, M. Sheds Extratores e Captadores de Ar Para Indução da Ventilação Natural em Edificações. São Paulo, 2015. Tese (Doutorado em Arquitetura e Urbanismo) Instituto de Arquitetura e Urbanismo de São Carlos, Universidade de São Paulo, São Paulo, 2015.

PERÉN, J. I. et al. CFD Simulation of WindDriven Upward Cross Ventilation and Its Enhancement in Long Buildings: impact of singlespan versus double-span leeward sawtooth roof and opening ratio. Building and Environment, v. 96, p. 142-156, 2016.

PERÉN, J. I. et al. Impact of Eaves on CrossVentilation of a Generic Isolated Leeward Sawtooth roof Building: windward eaves, leeward eaves and eaves inclination. Building and Environment, v. 92, p. 578-590, 2015.

PRATA, A. R. Impacto da Altura de Edifícios nas Condições de Ventilação Natural no Meio urbano. São Paulo, 2005. Tese (Doutorado em Arquitetura e Urbanismo) - Faculdade de Arquitetura e Urbanismo, Universidade de São Paulo, São Paulo, 2005.

PREVAT, D. O.; ASCE P. E. M.; ASCE, M. B. C. Wind Tunnel Studies on Sawtooth and Monosloped Roofs. Journal of structural engineering, v. 136, p. 1161-1171, 2010.
RAMPONI, R.; BLOCKEN, B. CFD. Simulation of Cross-Ventilation For a Generic Isolated Building: impact of computacional parameters. Building and Environment, v. 53, p. 34-48, 2012.

RORIZ, M. Arquivos Climáticos de Municípios Brasileiros. Associação Nacional de Tecnologia do Ambiente Construído. Grupo de Trabalho sobre Conforto e Eficiência Energética de Edificações. Relatório Interno, 2012. Disponível em: <http: www.labeee.ufsc.br/downloads/arquivosclimaticos>. Acesso em: 12 maio 2012.

STATHOPOULOS, T.; SAATHOFF, P. Codification of Wind Pressure coefficients for Sawtooth Roofs. Journal of Wind Engineering \& Industrial Aerodynamics, v. 43, n. 1/3, p. 17271738, 1992.

TOMINAGA, Y. et al. Comparasion of Various Revised k-e Models and LES Applied to Flow Around a High-Rise Building Model With 1:1:2 Shape Placed Within the Surfasse Boundary Layer. Journal of Wind Engineering \& Industrial Aerodynamics, v. 98, p. 65-78, 2008.

TORRES, D.; ADELINO, T.; BITTENCOURT, L. Análise da Utilização de Sheds Como Estratégia Passiva de Ventilação em Casa Geminada. In: ENCONTRO NACIONAL DE CONFORTO NO AMBIENTE CONSTRUÍDO, 12.; ENCONTRO LATINOAMERICANO DE CONFORTO NO AMBIENTE CONSTRUÍDO, 8., Brasília, 2013. Anais... Brasília, 2013.

\section{Agradecimentos}

Os autores agradecem à Fundação de Amparo à Pesquisa do Estado de São Paulo (FAPESP), pelo financiamento da presente pesquisa (Processo $\mathrm{n}^{-0}$ 2011/11376-6). 
Marieli Azoia Lukiantchuki

Departamento de Arquitetura e Urbanismo, Centro de Tecnologia | Universidade Estadual de Maringá | Zona 7| Maringá - PR - Brasil | CEP 87020-900 | Tel.: (44) 3011-4429 | E-mail: mlukiantchuki@yahoo.com.br

\section{Alessandra Rodrigues Prata-Shimomura}

Faculdade de Arquitetura e Urbanismo | Universidade de São Paulo | Rua do Lago, 876, Butantã | São Paulo - SP - Brasil | CEP 05508-080 | Tel.: (11) 3091-4681 Ramal 213 | E-mail: arprata.shimo@gmail.com

\section{Fernando Marques da Silva}

Departamento de Estruturas | Laboratório Nacional de Engenharia Civil | Av. do Brasil, 101 | Lisboa - Portugal | CEP 1700-066 | Tel.: +351 (21) 8443862 | E-mail: fms@lnec.pt

\section{Rosana Maria Caram}

Instituto de Arquitetura e Urbanismo | Universidade de São Paulo | Av. Trabalhador Sancarlense, Parque Arnold Schimidt | São Carlos - SP - Brasil | Caixa Postal 031 | CEP 13566590 | Tel.: (16) 3373-9308 Ramal 9308 | E-mail: rmcaram@sc.usp.br

\section{Revista Ambiente Construído}

Associação Nacional de Tecnologia do Ambiente Construído

Av. Osvaldo Aranha, 99 - 3o andar, Centro

Porto Alegre - RS - Brasil

$$
\text { CEP 90035-190 }
$$

Telefone: +55 (51) 3308-4084

Fax: +55 (51) 3308-4054

www. seer. ufrgs. br/ ambienteconstruido

E-mail: ambienteconstruido@ufrgs.br

176 Lukiantchuki, M. A.; Prata-Shimomura, A. R.; Silva, F. M. da; Caram, R. M. 